\title{
THE CENTRAL NERVOUS SYSTEM AND THE CONTROL OF PITUITARY HORMONE RELEASE IN THE PIG
}

\author{
F. ELLENDORFF and N. PARVIZI \\ Institut für Tierzucht und Tierverhalten Mariensee (FAL), 3057 Neustadt 1, \\ Federal Republic of Germany
}

Domestic animals have been recognized as Nobel prize winning sources of biological material. For example, the ox served to identify oxytocin (du Vingneaud, Barlett and Johl, 1954), the sheep (Burgus et al., 1971) and the pig (Schally et al., 1971) to characterize gonadotrophin releasing hormones. 'As yet physiologists, in particular neuro-endocrinologists, have only taken limited advantage of them experimentally. Since this symposium is devoted to pig reproduction, we shall attempt to present what is

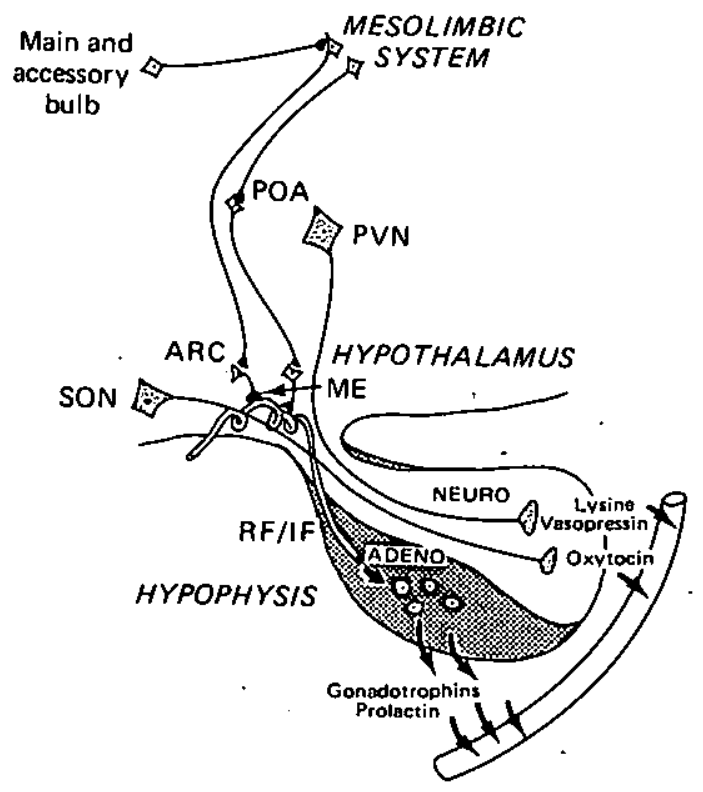

Figure 9.1 Schematic diagram of neuroendocrine systems known to be involved in pituitary hormone secretion and reproductive functions in the pig. ARC: arcuate nucleus; Main and accessory bulb: comprises the main and accessory olfactory system. ME: median eminence; forms together with ARC, ME and ventromedial nucleus of the hypothalamus the mediobasal hypothalamus; Mesolimbic System: comprising the limbic system including amygdala and hippocampus and the mesencephalon; POA: preoptic area; PVN: paraventricular nucleus; RF/IF: releasing/inhibiting factors; SON: supraoptic nucleus 
known on the control of pituitary hormone secretion by the central nervous system (CNS) in this species. Two systems will be of concern both pre- and postnatally: CNS control over luteinizing hormone (LH) secretion by the anterior pituitary and mechanisms leading to the release of the neurohormones oxytocin and vasopressin.

The systems controlling pituitary hormone secretion are beyond any doubt situated within the brain but not exclusively within the hypothalamus.(Figure 9.1). Extrahypothalamic areas, especially the limbic system and the mesencephalon, play a definite role and the portal vessels serve to channel releasing and inhibiting hormones from the region of the median eminence into the pituitary. Paraventricular and supraoptic neurohormones are sent via axons of the pituitary stalk into the posterior pituitary for storage and release. Although the electrical and neurochemical events of the brain constitute the common underlying mechanisms for the stimulation or inhibition of synthesis and release of neurosecretory materials, such as the releasing or inhibiting hormones, or oxytocin and vasopressin, factors other than those inherent to the CNS participate in their release. Thus peripherally-produced steroids, or nervous reflexes originating peripherally, are able to modulate neurosecretory activity and the pheromones may also be part of the control system. In reviewing current knowledge of the neuroendrocinology of the pig we shall limit our presentation to direct, rather than circumstantial, evidence for CNS control over hypophysial function and thus to an involvement of the brain in the control of reproduction in the pig.

\section{Foetal and adult brain control of $\mathrm{LH}$ secretion}

Brain control over pituitary hormone secretion probably commences well before the foetus turns to independent life. For the pig our laboratory investigated a number of elements of the secretion of $\mathrm{LH}$ both in chronically catheterized, unanaesthetized foetuses and in acute experiments. Measurable levels of LH were present during foetal life (Elsaesser et al., 1976; Colenbrander et al., 1977); furthermore the foetal pituitary could be stimulated by synthetic LH releasing hormone under in vivo and in vitro conditions (for details and references see Elsaesser, Chapter 5). However, this does not necessarily imply that the hypothalamus is already capable of releasing sufficient $\mathrm{LH}$ releasing hormone to trigger the release of LH into the circulation arid even in the adult a single pulse of $\mathrm{LH}$ releasing hormone does not seem to reflect the natural mechanisms of release. However, essential differences in the electrical activity (Figure 9.2) of cortical brain structures between the late prenatal and the pubertal pig are not obvious (Konda et al., 1979) and this reduces the likelihood that the late prenatal brain might not be capable of functioning in a postnatal fashion.

We have therefore stimulated the foetal hypothalamus electrically and electrochemically at various foetal ages (Bruhn, Parvizi and Ellendorff, 1981 and unpublished). An LH response was virtually absent on day 60; however detectable stimulation of foetal plasma LH levels could be evoked at day 80 and were clearly observed at 105 days of age. It is thus evident 


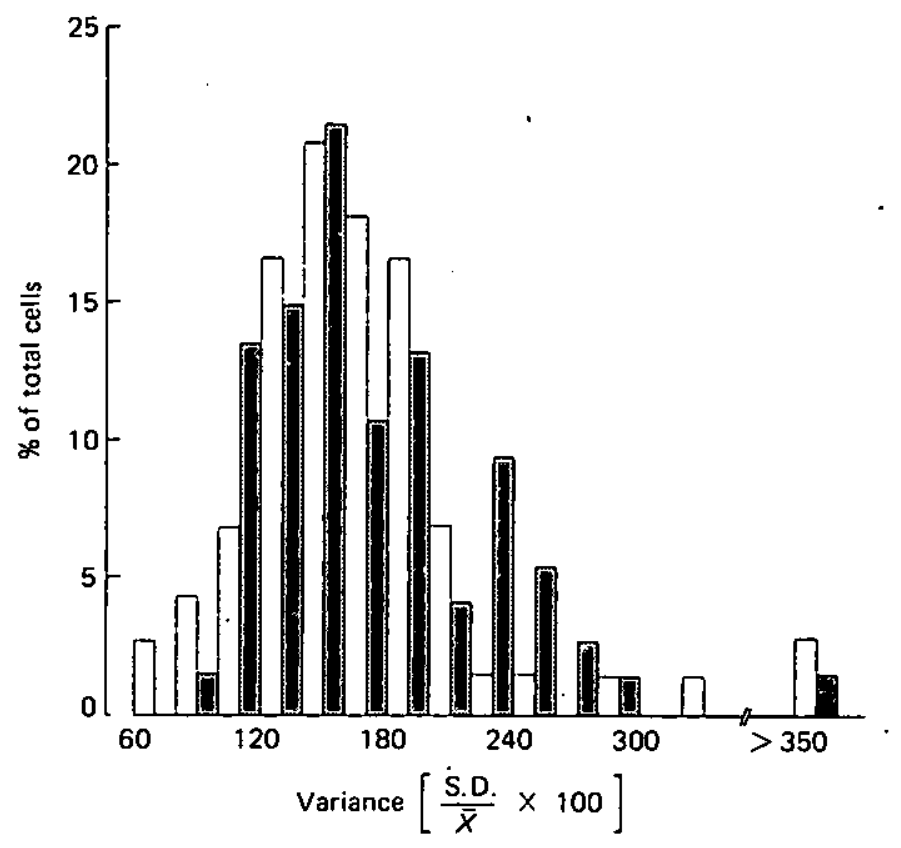

Figure 9.2 Comparison of distribution of variance in firing rate of single units recorded from cerebral cortex of prepubertal (hatched bars, $n=77$ units) and foetal (open bars, $n=72$ units) pigs. No significant difference existed. By courtesy of Konda et al. (1979)

that somewhere between days 60 and 80 the brain-pituitary axis advances sufficiently in its maturation to be capable of exerting control over the secretion of $\mathrm{LH}$ releasing hormone from hypothalamic nerve terminats. The pituitary portal vessels must be able to pass this information on to the anterior pituitary which also becomes responsive prior to and around day 80 . These observations have provided us with a time period over which to study the ontogeny of the other mechanisms involved in brain control over pituitary hormone secretion.

The only evidence that manipulation of the postnatal but prepubertal brain subsequently affects reproduction in the female pig indicates that mediobasal and anterior hypothalamic lesions, as well as constant illumination, result in anovulation (Döcke and Busch, 1974). This is probably due to an absence of the LH surge since polyfollicular ovaries were present.

In the adult pig more extensive investigations have been carried out. Undoubtedly, a number of hypothalamic and extrahypothalamic brain areas can be stimulated in the pig with consequent changes in the blood levels of pituitary secretions. However, such responses are not always as uniform as might be expected when compared with a multitude of experiments in the rat and other smaller species, although there are possible experimental reasons for such differences, the most important being the much higher structural resolution that can be achieved in the pig's brain when compared with smaller species. Although changes in plasma $\mathrm{LH}$ in response to electrical stimulation of discrete brain areas are indicative of general brain control over pituitary $\mathrm{LH}$ release, it is known 
from many studies in small laboratory species that apart from the mediobasal hypothalamus and the preoptic area, the limbic and mesencephalic structures must be taken into account when considering the regulation of gonadotrophin secretion and this topic has been discussed elsewhere (Ellendorff, 1978; Ellendorff and Parvizi, 1980). Moreover, at any level (be it the amygdala, hippocampus, mesencephalon or the hypothalamus), the steroids, the classical neurotransmitters and the neuropeptides are essential in contributing to any changes in $\mathrm{LH}$ releasing hormone and finally $\mathrm{LH}$ release, and there is no reason to believe that the pig should differ in basic principles of design.

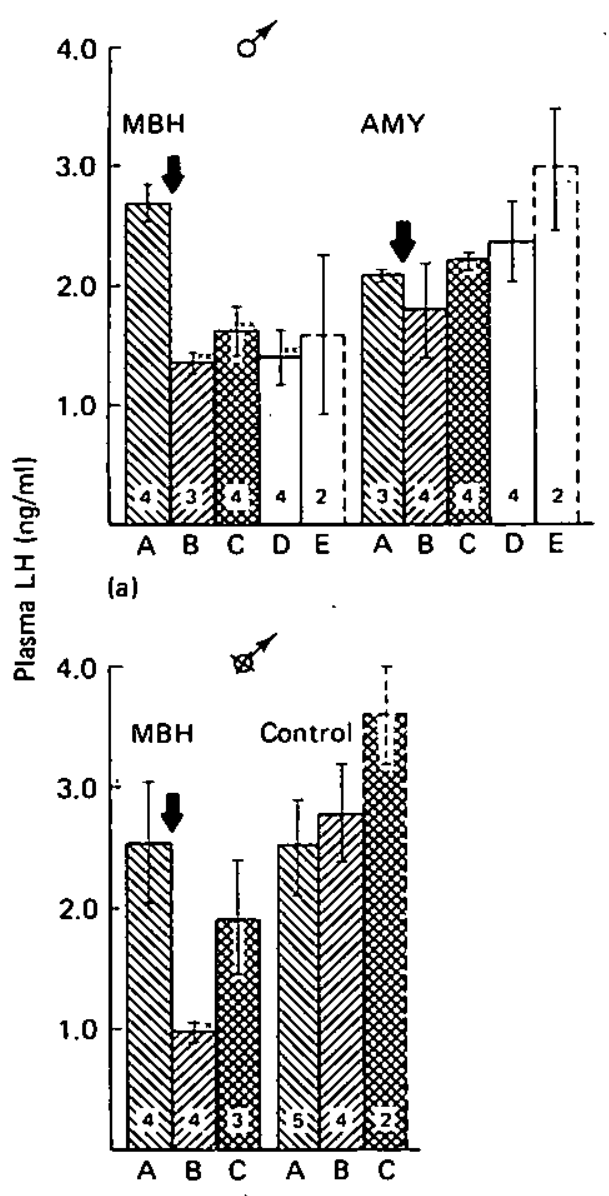

(c)

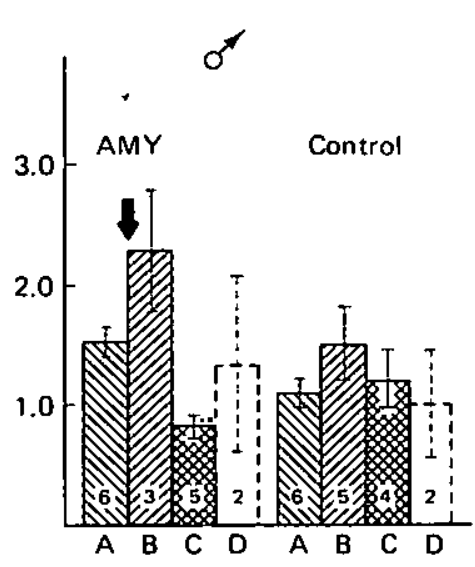

(b)

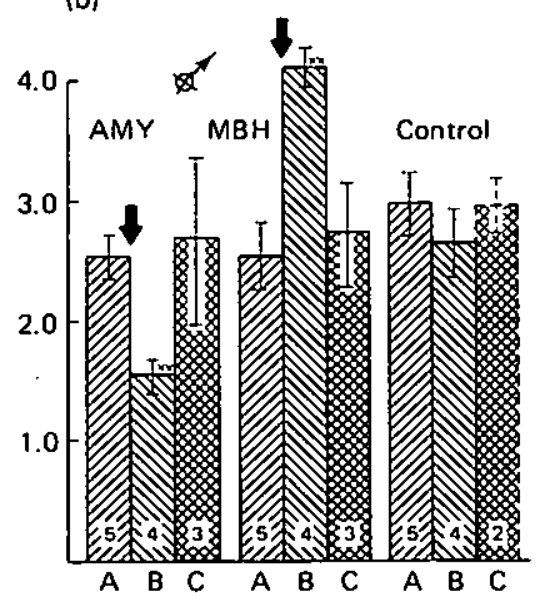

(d)

Figure 9.3 Examples of plasma LH response to electrical stimulation of the mediobasal hypothalamus (MBH) and the amygdala (AMY) in (a) and (b) intact male, (c) and (d) castrated male. All animals were chronically implanted and unanaesthetized. Stimulus parameters: $100-200 \mu \mathrm{A}, 100 \mathrm{~Hz}, 0.5 \mathrm{~ms} 30 \mathrm{~s}$ on/off, $60 \mathrm{~min}$, each stimulation at least two days apart. A: prior to stimulation; B: up to $60 \mathrm{~min}$; C: $60-120 \mathrm{~min}$; D: 140-200 min; E: 220-240 min post stimulation. Numbers in columns indicate numbers of samples taken at 10-20 min intervals. Arrows indicate onset of stimulation. From Ellendorff and Parvizi (unpublished) 
In testing such interactions experimentally the intact and castrate male pig has been the model of preference. Electrical stimulation of various brain structures in the unanaesthetized male pig resulted in altered plasma levels of LH (Figure 9.3) (Ellendorff et al., 1973). Five of six orchidectomized boars had lowered plasma LH concentrations following amygdala stimulation and one did not change relative to controls. The response of intact males was not as clearly defined; of five boars stimulated two displayed increased, and one decreased, plasma $\mathrm{LH}$ levels and in one there was no change. Stimulation of the mediobasal hypothalamus (MBH), however, produced more equivocal results. We hypothesize therefore that gonadal steroids and/or differences in the levels of circulating gonadotrophins which have been reported previously in castrate and intact boars (Pomerantz et al., 1974) were responsible for the differences observed.

It is now well established in all species investigated that steroid receptors are present in at least the amygdala and hypothalamus. However, if functional significance is to be attributed to such binding or localization studies, peripheral as well as local application of steroids should result in measurable responses, e.g. changes in plasma LH levels. In the orchidectomized pig intramuscular injections (Figure 9.4 (c) and (d)) of testosterone (T), as well as oestradiol $\left(E_{2}\right)$, lowered plasma levels of $\mathrm{LH}$ within 24 hours, irrespective of the two dose levels given $(15 \mathrm{mg}$ and $6.0 \mathrm{mg}$ for $\mathrm{T}$ and $1.5 \mathrm{mg}$ and $0.6 \mathrm{mg}$ for $E_{2}$ per $\mathrm{kg}$ body weight). $5 \alpha$-Dihydrotestosterone $(5 \alpha$-DHT) evoked an increase in plasma LH when given at a lower dose $(6 \mathrm{mg} / \mathrm{kg})$; however at considerably higher concentrations $(15 \mathrm{mg} / \mathrm{kg})$ LH levels were significantly depressed when compared with levels prior to treatment and in untreated controls (Parvizi et al., 1977). Although the responses to testosterone and oestradiol were consistent with results from other species, the stimulatory effect of $5 \alpha$-DHT on LH secretion was unexpected and appears to be unique to the pig.

At least some of these effects should be due to the action of steroids on the hypothalamus and/or the amygdala. Microinjections of testosterone, oestradiol or $5 \alpha$-DHT were therefore first placed into the amygdala of castrated males (Figure 9.4(e)). The outcome for testosterone and oestradiol was initially rather disappointing: $60 \mathrm{ng}$ testosterone or $6 \mathrm{ng} 17 \beta-$ oestradiol did not alter plasma LH levels in $6 / 7$ and in $5 / 6$ animals respectively $2,4,24$ or 48 hours after application. In contrast, when $5 \alpha$-DHT (60 ng) was given to six animals, significantly elevated plasma $\mathrm{LH}$ was recorded in two animals within 4 hours, in four animals within 24 hours and in five animals within 48 hours after application to the amygdala. Initially we concluded that in the castrated male pig $5 \alpha$-DHT participates in the regulation of $\mathrm{LH}$ secretion by a stimulatory role that is localized in the amygdala and becomes effective within 48 hours of exposure. It has been shown in other Chapters that rather striking effects of gonadal steroids (oestrogens) on LH secretion take much longer to develop. It is possible, however, that single microinjections of testosterone and of oestradiol in the amygdala are ineffective due to their rapid metabolism, or that the amygdala is not a location in which it is possible to provoke testosteronemediated changes in LH. In order to test these possibilities crystalline testosterone or $5 \alpha$-DHT was implanted into the mediobasal hypothalamus or the amygdala (Figure 9.4(a) and $(b)$ ) to assure a longer lasting exposure 

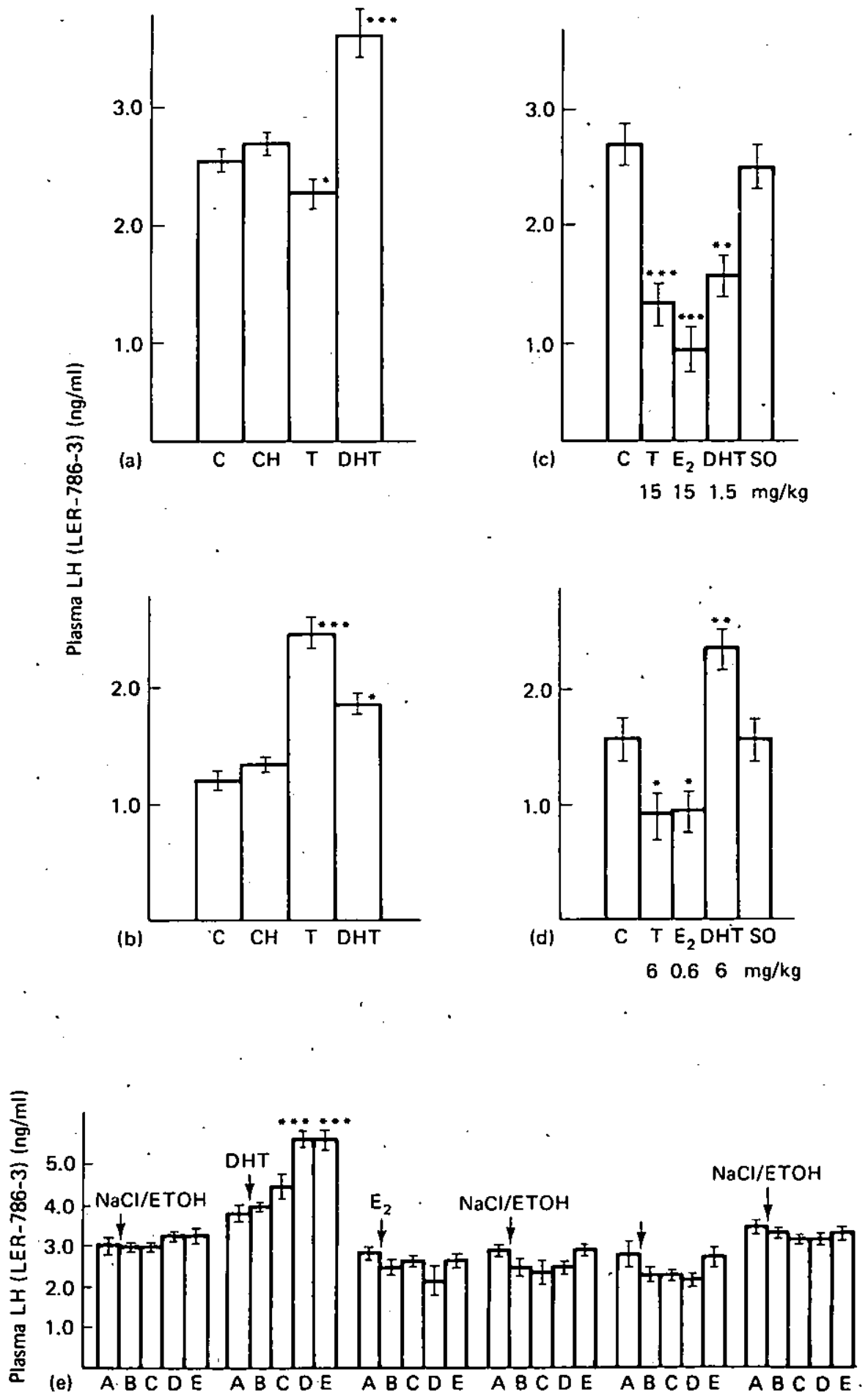
of each structure (Parvizi et al., 1977). This time, 5/7 animals with testosterone implants in the amygdala reacted with slightly, but significantly, lowered plasma LH levels for a period of 10 days after the implant had been introduced (two animals showed no response). On the other hand, a clear increase in LH was observed when testosterone was placed into the mediobasal hypothalamus. 5 $\alpha$-DHT caused a stimulation of LH levels from both locations. We further concluded, therefore, that in the pig $5 \alpha$-DHT exerts its positive effects on plasma LH both at the amygdala and $\mathrm{MBH}$ in short and long-term exposure situations.

Testosterone, on the other hand, is more difficult to characterize. It can be inhibitory or stimulatory to $\mathrm{LH}$ secretion depending on the site of accumulation and the duration of action. Alternatively, testosterone or its metabolites as well as other steroids, may induce immediate changes in the neurons to which they are attached, but these changes do not necessarily find an immediate expression in changing LH levels under normal conditions.

One hypothesis is that steroids either alter the sensitivity of neurons to incoming electrical impulses or alter the threshold for outgoing signals (e.g. action potentials). If this is true, then alterations in $\mathrm{LH}$ levels induced by electrical stimulation should be modifiable by prior exposure to steroids of the area to be stimulated. We have already mentioned that electrical stimulation of the amygdala in the orchidectomized pig per se usually decreases plasma LH levels and that microinjections of testosterone alone have no effect on LH. If, however, testosterone was microinjected prior to electrical stimulation, the expected decreasing effects of electrical stimulation on LH were not only abolished, but plasma LH was significantly elevated in $5 / 6$ animals within 210 minutes after application of an electrical current to the amygdala (Figure 9.5). Oestradiol and $5 \alpha$-DHT only abolished the LH decline (Parvizi and Ellendorff, 1980a) evoked by electrical stimulation alone. Thus a modulatory role of testosterone and its metabolites $5 \alpha$-DHT and oestradiol can be postulated for the amygdala. Under what circumstances the fast or slow components become effective is not known.

Very little is known about mechanisms involved in these modulating effects. A link to neurotransmitter metabolism is suggested since some oestrogen metabolites (hydroxylated oestrogens, catecholoestrogens)

Figure 9.4 (opposite) (a), (b): Plasma LH after successive implantation of $5 \alpha$ dihydrotestosterone (DHT: cholesterol, 1:2); testosterone (T: cholesterol, 1:2), cholesterol (CH) or no treatment (C) into (a) the amygdala, (b) the mediobasal hypothalamus of two individual miniature pigs.

(c), (d): Different effects of $5 \alpha$-dihydrotestosterone (DHT) and the effects of testosterone (T), 17 $\beta$-oestradiol $\left(E_{2}\right)$, sesame oil (SO) or no treatment (C) on plasma LH secretion in the castrated male miniature pig. Samples were taken 24 hours after injection.

(e): Responses of an individual animal to microinjection into the amygdala of $2 \mu \mathrm{l} \mathrm{NaC1-}$ EtOH $(7 \mathrm{ml} 0.9 \% \mathrm{NaCl}+3 \mathrm{ml} 20 \%$ ethanol), $60 \mathrm{ng} 5 \alpha$-dihydrotestosterone (DHT), $6 \mathrm{ng}$ $17 \beta$-oestradiol $\left(E_{2}\right)$ and $60 \mathrm{ng}$ testosterone $(\mathrm{T})$ each dissolved in $2 \mu \mathrm{l} \mathrm{NaCl}-\mathrm{E}$ iOH. Arrows indicate time of injection. Seven to nine samples per block, obtained at 15 minute intervals. Each column (B-E) was compared with the corresponding control period $(A)$. $A=0-2$ hours before microinjection; $B=0-2$ hours after microinjection; $C=2-4$ hours after microinjection; $D=24-25$ hours after microinjection; $E=48-49.5$ hours after microinjection. Asterisks denote degree of significance: ${ }^{*} P<0.05 ;{ }^{*} P<0.01$; ${ }^{* *} P<0.001$. By courtesy of Parvizi $e t$ al. (1977) 


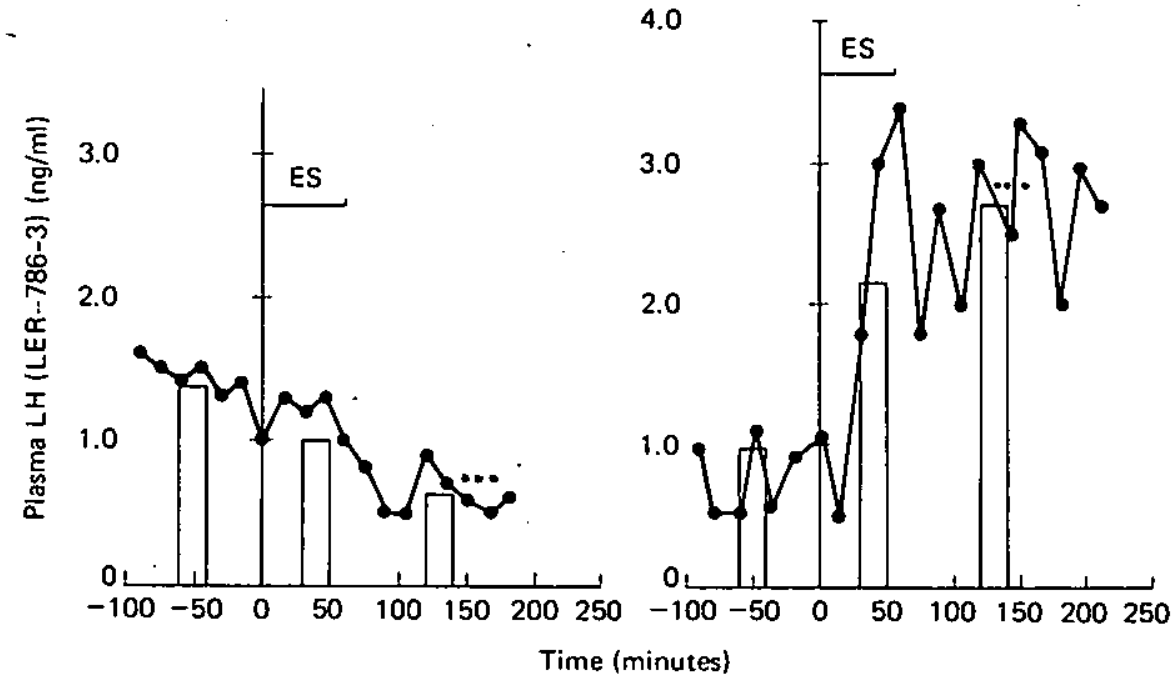

DHT

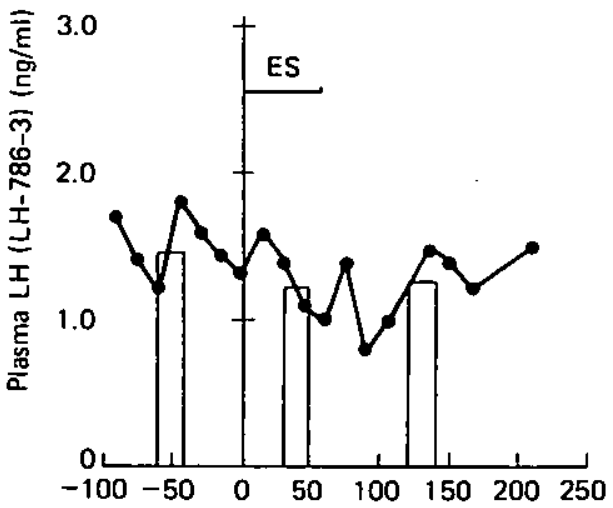

Oestradiol

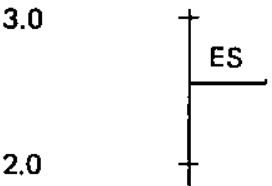

3.0

$\begin{array}{lllllll}-100-50 & 0 & 50 & 100 & 150 & 200 & 250\end{array}$

Time (minutes)

Figure 9.5 Plasma LH levels in single animals which had been microinjected with steroids into the amygdala 210 minutes prior to the onset of electrical stimulation of the amygdala. Control: No prịor microinjection; Testosterone, DHT: Animals received $60 \mathrm{ng}$ of either substance in $1 \mu \mathrm{l}$ of solvent; Oestradiol: Animal received $6 \mathrm{ng}$ in $1 \mu \mathrm{l}$. ES: Electrical stimulation $10 \mathrm{~Hz}, 100 \mu \mathrm{A}, 0.1 \mathrm{~ms}, 30 \mathrm{~s}$ on/off, $60 \mathrm{~min}{ }^{* *} P<0.001$. From Parvizi and Ellendorff (1980a)

compete with catecholamines for catechol-O-methyl-transferase (COMT) (Breuer, Vogel and Knuppen, 1962). Higher affinity of COMT for 2-OH-oestrogens should, for instance, result in the accumulation of norepinephrine and therefore induce similar effects to norepinephrine. The pig was the first species in which a direct application of catecholoestrogens into the brain was attempted (Parvizi and Ellendorff, 1975). Microinjections of $60 \mathrm{ng} 2-\mathrm{OH}$-oestradiol $\left(2-\mathrm{OHE}_{2}\right)$ into the amygdala 


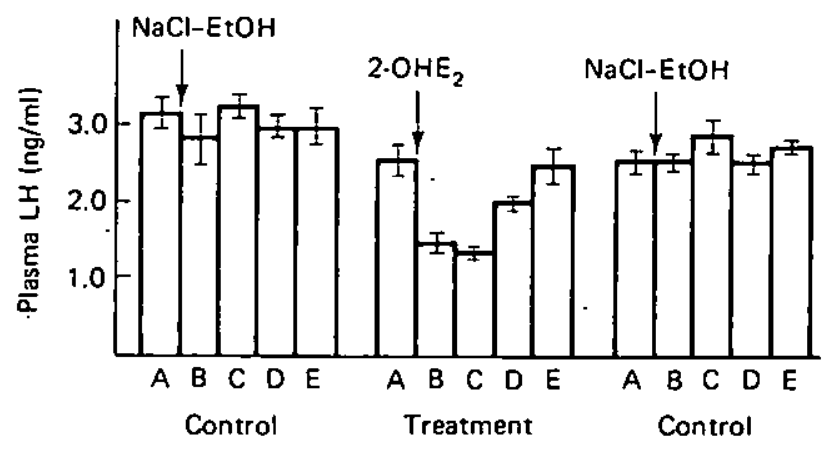

Figure 9.6 Plasma LH (mean \pm S.E.M.; LER-786-3) after microinjection of 2-OHoestradiol $\left(2-\mathrm{OHE}_{2}\right)$ into the amygdala of an individual orchidectomized adult miniature pig. $\mathrm{NaCl}-\mathrm{EtOH}: 2 \mu \mathrm{l}$ of a stock made from $7 \mathrm{ml} 0.9 \% \mathrm{NaCl}$ and $3 \mathrm{ml} 20 \% \mathrm{EtOH} ; 2-\mathrm{OHE}_{2}: 2 \mu \mathrm{l}$ $\mathrm{NaCl}-\mathrm{EtOH}$ containing $60 \mathrm{ng} \mathrm{OHE}_{2}$ (seven to nine samples per block obtained at 15 minute intervals). Each column (B-E) was compared with the corresponding control period (A) by

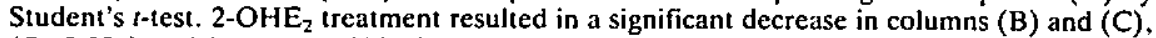
$(P \leqslant 0.001)$ and in column (D), $(P \leqslant 0.01) . A=0-2$ hours before microinjection; $\mathrm{B}=0-2$ hours after microinjection; $C=2-4$ hours after microinjection; $D=24-25.5$ hours after microinjection, $E=48-49.5$ hours after microinjection. By courtesy of Parvizi and Ellendorff (1975)

were followed by a decrease in plasma LH within 90 minutes (Figure 9.6). This relatively rapid response fitted well with the effects observed after testosterone, but not after oestradiol microinjections into the amygdala. Electrical stimulation following $2-\mathrm{OHE}_{2}$ microinjections affected the inhibition induced by electrical stimulation alone but in equivocal fashion (Figure 9.7). Microinjection of $2-\mathrm{OHE}_{2}$ into the hypothalamus also inhibited plasma LH levels in the intact male. If the above hypothesis is

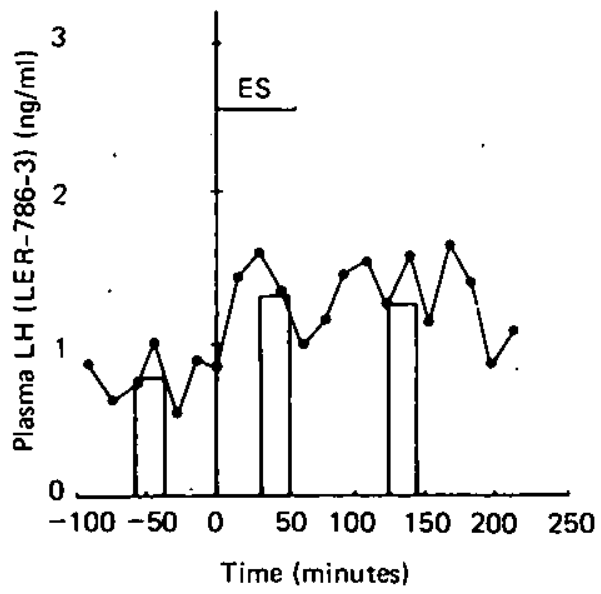

(a)

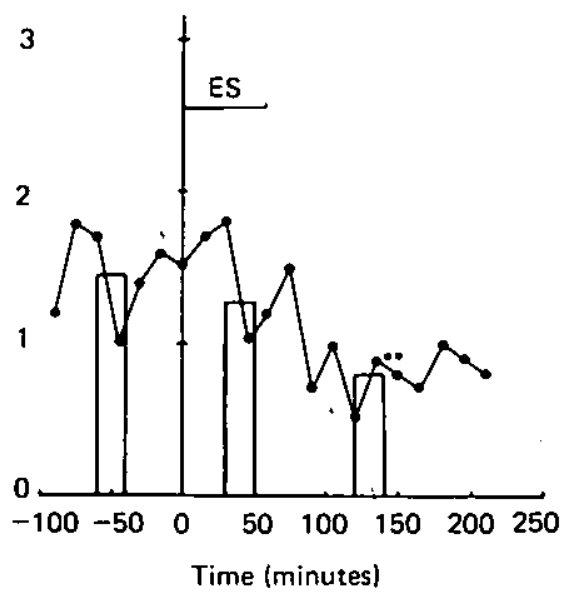

(b)

Figure 9.7 Response of two animals to electrical stimulation (ES) of the amygdala following microinjection of $2-\mathrm{OHE}_{2} 210$ minutes prior to ES. (a) 2-OHE 2 had lowered LH prior to the onset of ES; ES did not alter LH. (b) $2-\mathrm{OHE}_{2}$ had not altered LH levels prior to ES; ES lowered LH. "* $P<0.01$. By courtesy of Parvizi and Ellendorff (1980) 
true, we would also expect inhibition of LH secretion when the hypothalamus is exposed to norepinephrine and, indeed, when $60 \mathrm{ng}$ of norepinephrine was microinjected into the hypothalamus, 7/9 males responded with reduced plasma LH levels (Figure 9.8). Microinjections of $60 \mathrm{ng}$ norepinephrine into the third ventricle, on the other hand, induced a surge of LH in $4 / 4$ males similar to data reported for the rat (Schneider and McCann, 1970).

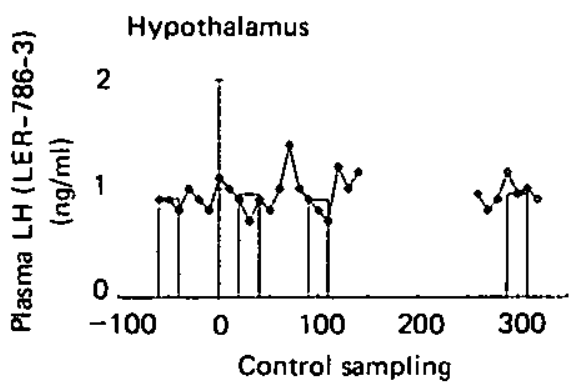

(a)

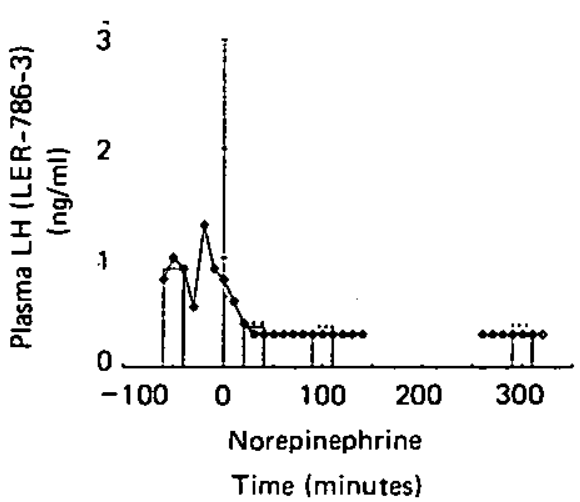

(c)

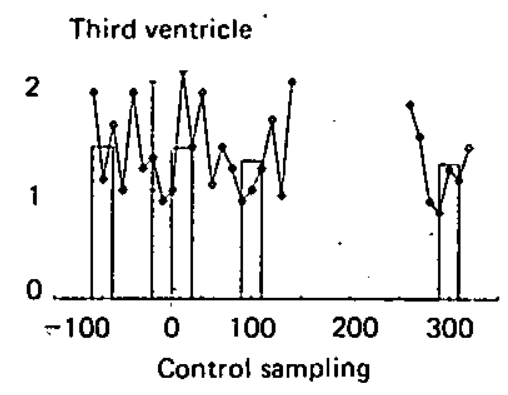

(b)

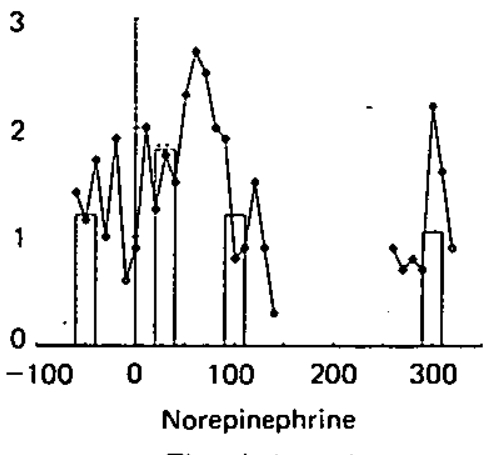

(d)

Figure 9.8 Effect of norepinephrine on LH secretion when microinjected into the mediobasal hypothalamus (a) versus (c) and the third ventricle (b) versus (d). By courtesy of Parvizi and Ellendorff (1978)

Apart from steroid-neurotransmitter interaction, the interference of neurobiologically-active peptides with the regulation of LH has become a focus of discussion. Peripheral injections of endorphins into small laboratory species affect the secretion of pituitary hormones (Bruni et al., 1977) and the hypothalamus has been suggested as the site of action. The microinjection of $\beta$-endorphin into the hypothalamus or amygdala of the pig (Parvizi and Ellendorff, 1980b) suggests that it is not the hypothalamus but the amygdala in which $\beta$-endorphin becomes effective (Figure 9.9). .If $\beta$-endorphin was microinjected simultaneously into the amygdala and hypothalamus, a small enhancement of the LH decline was observed when compared with a microinjection into the amygdala alone. This may give a 


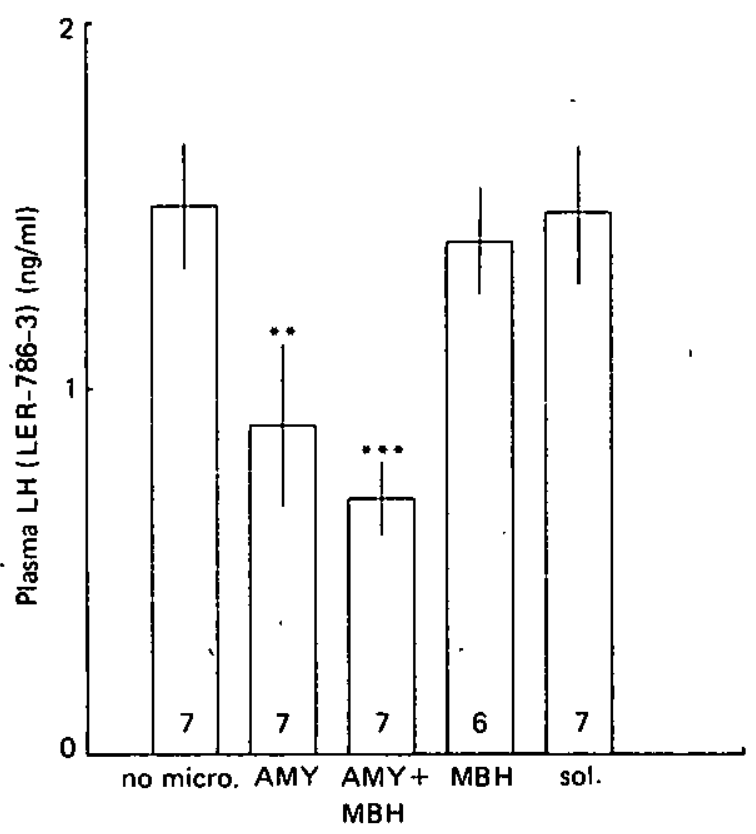

Figure 9.9 Decrease of plasma LH levels $100-180$ minutes after microinjection of $30 \mathrm{ng}$ $\beta$-endorphin into the amygdala (AMY) or mediobasal hypothalamus (MBH) or both ' $(\mathrm{AMY}+\mathrm{MBH})$ of ovariectomized miniature pigs. 'No micro' = control blood sampling without any treatment; 'Sol.' = microinjection of $1 \mu \mathrm{l}$ of $9.7 \%$ saline. Numbers in the bars represent the number of animals. For statistical analysis the period of sampling was divided into three blocks each of nine successive samples taken at 10 minute intervals. The mean LH value for each animal within each block was calculated. A one-way analysis of variance was then carried out to detect differences among mean $L H$ values of treatments and time blocks. ${ }^{* *} P<0.01 ;{ }^{* *} P<0.001 ; \bar{x} \pm$ S.E.M. By courtesy of Parvizi and Ellendorff (1980b)

first insight into a most complex system of regulation of gonadotrophin secretion by neuroactive peptides in the pig as well as in other species.

\section{OLFACTION}

A discussion of the central nervous system and the control of reproduction in the pig would be incomplete without mentioning the olfactory system. It is unique because the steroidal pheromones produced by the boar have been identified and are available synthetically. The interest of the neuroendocrinologist centres around its uptake and the possible transmission of pheromonal information within the CNS. The olfactory system of the pig is essentially the same as that of other mammals (Reinhardt et al., 1981). The mitral cell layer of the main olfactory bulb receives input from the olfactory nerves and passes the information on via the lateral olfactory tract (LOT) to higher centres, including the amygdala and, to a lesser extent, the hypothalamus. These connections are often reciprocal. If $5 \alpha$-androst-16ene-3-one $(\Delta-16)$ and $3 \alpha$-hydroxy-5 $\alpha$-androst-16-ene are pheromones, they could become effective via the olfactory system, though other forms of uptake, e.g. the nasal mucosa, should not be discarded. 

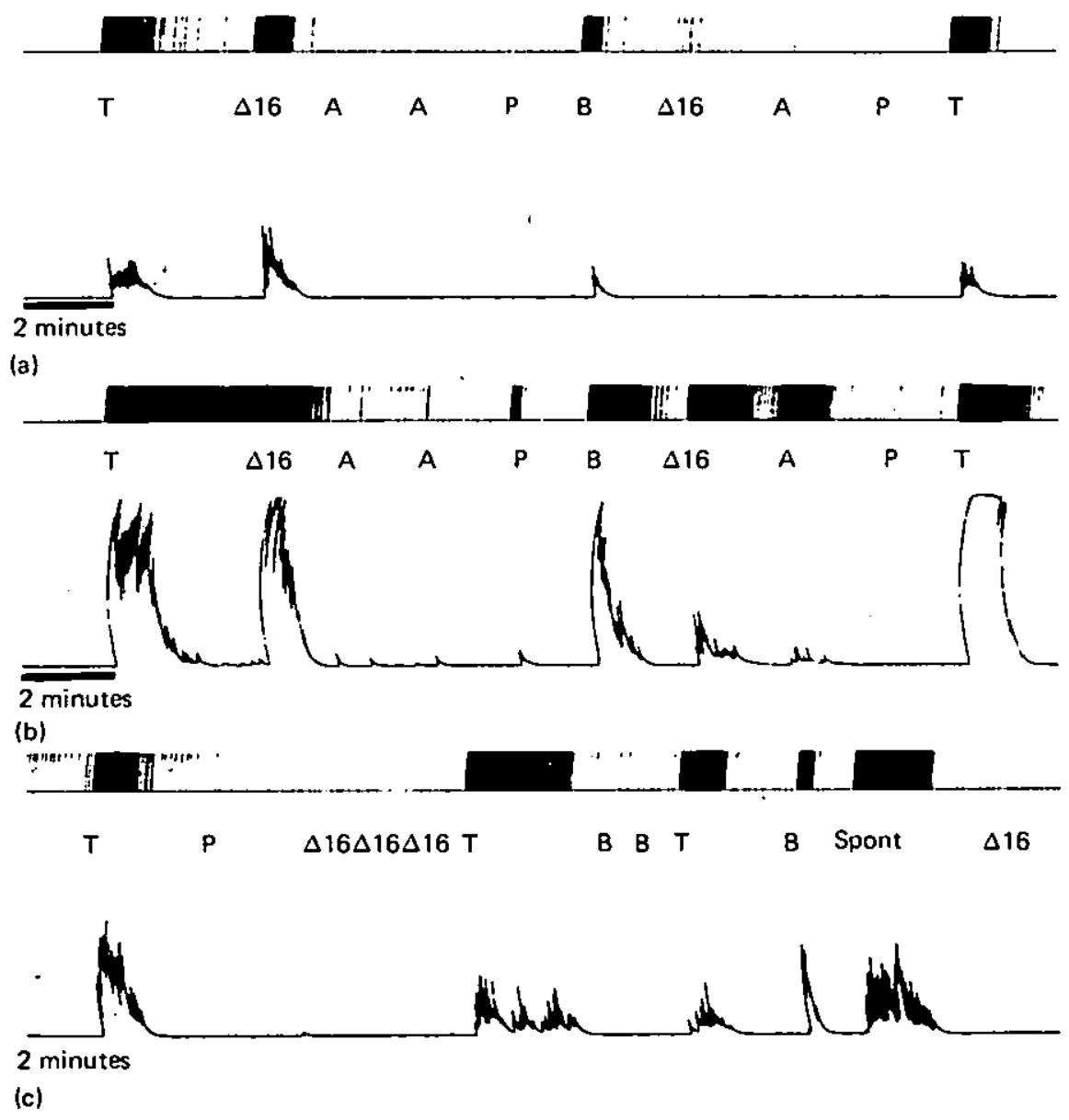

Figure 9.10 Polygraph recording of neural activity. Each pen deflection on the upper traces represents four action potentials; the lower trace is an integrated record of this activity derived from cell action potentials. (a) and (b) two neurons responded to both $5 \alpha$-androst-16ene-3-one $(\Delta-16)$ and testosterone (T). In (c) neurons responded to $T$ but only $2 / 10$ stimuli responded to $\Delta-16$. Other organic substances tested: $\mathrm{A}=$ Amylacetate; $\mathrm{P}=$ Pyridine; $\mathrm{B}=$ Benzene. Spont $=$ a spontaneous burst of firing. By courtesy of MacLeod, Reinhardt and Ellendorff (1979)

In the pig both $\Delta-16$ and testosterone alter the electrical activity of mitral neurons after exposure of the olfactory system to aerosols of these substances (Figure 9.10), and the neurons may be activated by both or either one of the steroids indicating discriminatory abilities of the olfactory system for steroids. The connections to the amygdala could be one pathway by which behavioural or endocrine changes may be brought about. In addition to the main olfactory system, the accessory olfactory system may be involved in reproductive functions (Ladewig, Price and Hart, 1980). This is well developed in the pig with a nasopalatine duct allowing access to the vomeronasal organ from where fibres project over the surface of the main bulb into the accessory bulb. 


\section{Oxytocin and vasopressin secretion}

The neurohypophysis, like the anterior pituitary, is also able to secrete its hormones prenatally, so the magnocellular neurosecretory system of the paraventricular and supraoptic nuclei must be functional in the foetal pig. Circulating levels of oxytocin and lysine vasopressin (LVP) are detectable at the foetal age of 75 and 109 days respectively. In fact, concentrations of both hormones exceed those found in simultaneous maternal samples (MacDonald et al., 1979). In addition, the foetus responds with elevated LVP levels when exposed to haemorrhage (Forsling, Macdonald, and Ellendorff, 1979).

In the adult sow both parturition and nursing are associated with massive oxytocin release (Forsling et al., 1979). In late pregnancy oxytocin concentrations of sow plasma are close to the lower level of detection and only a few hours ( $<7$ hours) before foetal expulsion does the range of oxytocin release increase to about $24 \mu \mathrm{U}$ oxytocin $/ \mathrm{ml}$. Immediately after expulsion this value could be exceeded almost threefold and during delivery of the placentas a similar high surge of oxytocin occurs (Figure 9.11). It is likely that the extremely high concentrations of oxytocin are due

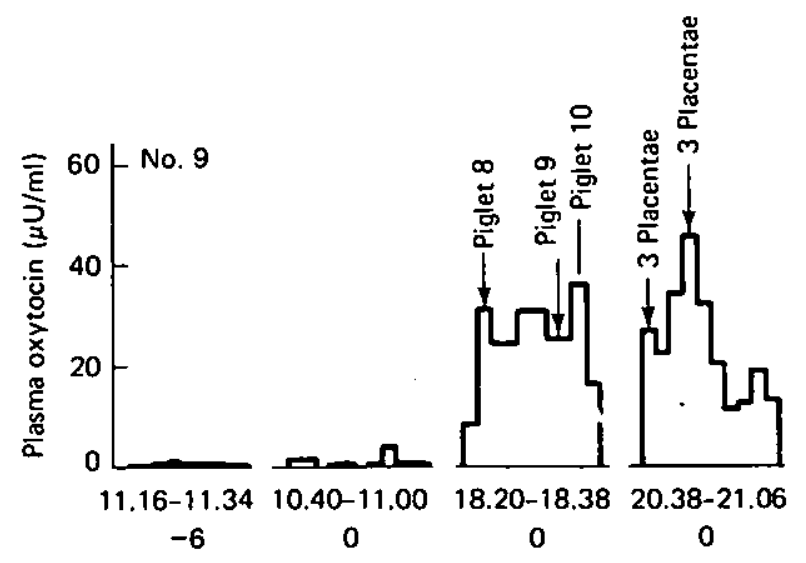

Time of day (hours)

Figure 9.11 Oxytocin secretion before, during and after parturition in the miniature pig. By courtesy of Forsling et al. (1979)

to mechanical stimulation of the cervix thus producing a Ferguson reflex release of oxytocin. It is not easy to explain the mechanisms leading to the initial release of oxytocin prior to expulsion of the first foetus, although several endocrine changes take place at this time. Plasma prostaglandin levels display a surge of release (Silver et al., 1979) and prostaglandins stimulate oxytocin release in the sow (Ellendorff et al., 1979). Oestrogens clearly reach their maximal values immediately prior to parturition (Shearer $e t$ al., 1972; Ash and Heap, 1975; Taverne $e t$ al., 1979) and progesterone declines rapidly just prior to and during parturition, when it is closely related to changing oxytocin levels (Forsling $e t$ al., 1979). It is also likely that the release pattern of oxytocin follows a cascade effect that has been 
proposed for the steep rise of a number of hormones prior to parturition (Thorburn, Challis and Currie, 1977).

The first evidence that oxytocin is responsible for milk ejection in the sow as in other species came from experiments in which injections of oxytocin (Whittlestone, 1954) produced a subsequent increase in intramammary pressure. Later some oxytocin measurements by bioassay (Folley and Knaggs, 1966) indicated a rise of oxytocin during the act of suckling. We have also observed that oxytocin levels were highest during suckling and lowest during periods of no suckling and higher peak levels of oxytocin occurred in early lactation when compared with later stages (Forsling et al., 1979).

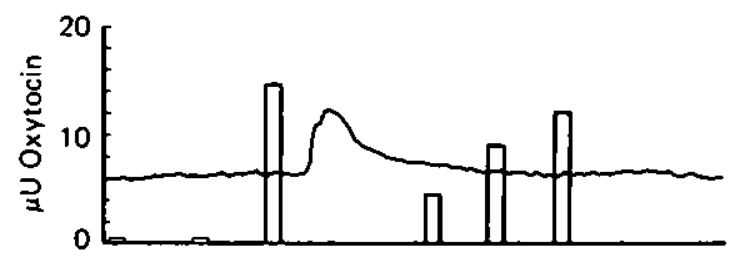

(a)

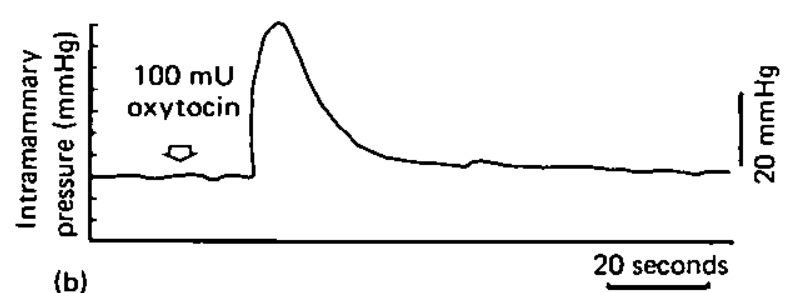

(b)

Figure 9.12 (a) Maternal milk ejection reflex in the sow displaying intramammary pressure changes and oxytocin secretion (open bars). (b) Induction of intramammary pressure changes and milk ejection with a single rapid injection of oxytocin. The relatively high dose evoked a much stronger response by the mammary gland. From Ellendorff, Forsling and Poulain (1981)

More recently a detailed analysis of oxytocin and time-linked events was undertaken (Ellendorff, Forsling and Poulain, 1981) and it was found that the suckling event that occurs every $40-50$ minutes is associated with a surge in oxytocin (Figure 9.12) in the absence of any appreciable increase in vasopressin secretion. The characteristic grunting pattern described previously in detail (Fraser, 1973) reaches its crescendo around the time of oxytocin release but is not always indicative of oxytocin release. The amount of oxytocin secreted during a successful milk ejection corresponds to about $10 \mathrm{mU}$ of oxytocin given as a single rapid injection. The signal initiating the secretion of oxytocin from the neurohypophysis is probably very similar to that described in the rat (for review see Cross et al., 1975). Oxytocin release and intramammary pressure changes are almost identical to the natural milk ejection when the posterior pituitary of the rat is stimulated at frequencies between 25 and $40 \mathrm{~Hz}$ under such experimental conditions; however, there is also significant release of vasopressin. A distinct difference to the rat exists in the pig (as probably in many other mammals) with respect to sleep patterns related to nursing. In contrast to 
the rat which invariably displays a slow wave sleep EEG (Lincoln $e t$ al., 1980; Voloschin and Tramezzani, 1979), a similar sleep pattern is not predictably associated with the onset of each suckling period in the pig (Poulain, Rodriguez and Ellendorff, 1981).

\section{References}

ASH, R.W. and HEAP, R.B. (1975). Oestrogen, progesterone and corticosteroid concentration in peripheral plasma of sows during pregnancy, parturition, lactation and after weaning. J. Endocr. 64, 141-154

BREUER, H., VOGEL, W. and KNUPPEN, R. (1962). Enzymatische Methylierung von 2-Hydroxy-Östradiol-(17 $\beta$ ) durch eine S-AdenosylMethionine-Acceptor-O-Methyltransferase der Rattenleber. HoppeSeyler's Z. physiol. Chem. 327, 217-222

BRUHN, T., PARVIZI, N. and ELLENDORFF, F. (1981). Ability of the fetal hypothalamus to alter LH-secretion in response to electrical and electrochemical stimulation. Acta endocr. 96, Suppl. 240, 46

BRUNI, J.F., van VUGT, D., MARSHALL, S. and MEITES, J. (1977). Effects of naloxone, morphine and methionine-enkephatin on serum prolactin, luteinizing hormone, follicle stimulating hormone, thyroid stimulating hormone and growth hormone. Life Sci. 21, 461-466

BURGUS, R., BUTCHER, M., LING, N., MONAHAN, M., RIVIER, J., FELLOWS, R., AMOSS, M., BLACKWELL, R., VALE, W. and GUILLEMIN, R. (1971). Structure moleculaire du facteur hypothalamique (LRF) d'origine ovine controlant la secretion de l'hormone de gonadotrope hypo-physaire du luteinisation. C. R. hebd. Seanc. Sci., Paris 273, 1611-1613

COLENBRANDER, B., DRUIP, TH.A.M., DIELEMAN, S.J. and WENSING, C.J.G. (1977). Changes in serum LH concentrations during normal and abnormal sexual development in the pig. Biol. Reprod. 17, 506-513

CROSS, B.A., DYBALL, R.E.J., DYER, R.G., JONES, C.W., LINCOLN, D.W. MORRIS, J.F. and PICKERING, B.T. (1975). Endocrine neurons. Recent Prog. Horm. Res. 31, 243-294

DÖCKE, F. and BUSCH, W. (1974). Evidence for anterior hypothalamic control of cyclic gonadotrophin secretion in female pigs. Endocrinology $63,415-421$

ELLENDORFF, F. (1978). Extra-hypothalamic centres involved in the control of ovulation. In Control of Ovulation, (D.B. Crighton, N.B. Haynes, G.R. Foxcroft and G.E. Lamming, Eds.), pp. 7-19. London, Butterworths

ELLENDORFF, F. and PARVIZI, N. (1980). Role of extrahypothalamic centres in neuroendocrine integration. In The Endocrine Functions of the Brain, (M. Motta, Ed.), pp. 297-325. New York, Raven Press

ELLENDORFF, F., FORSLING, M. and POULAIN, D. (1981). Plasma oxytocin levels associated with the milk ejection reflex in the sow. Acta endocr. 96, Suppl. 240, 49

ELLENDORFF, F., KREIKENBAUM, K., PARVIZI, N. and SMIDT, D. (1973). LH-secretion in response to electrical stimulation of the chronically implanted miniature pigs brain. Acta endocr. Suppl. 177, 73 
ELLENDORFF, F., FORSLING, M., PARVIZI, N. and WILLIAMS, H., TAVERNE, M. and SMIDT, D. (1979). Plasma oxytocin and vasopressin concentrations in response to prostaglandin injection into the pig. J. Reprod. Fert. 56, 573-577

ELSAESSER, F., ELLENDORFF, F., POMERANTZ, D.K., PARVIZI, N. and SMIDT, D. (1976). Plasma levels of luteinizing hormone, progesterone, testosterone and $5 \alpha$-dihydrotestosterone in male and female pigs during sexual maturation. J. Endocr. 68, 147-148

FOLLEY, S.J. and KNAGGS, G.S. (1966). Milk-ejection activity (oxytocin) in the external jugular vein blood of the cow, goat and sow, in relation to the stimulus of milking or suckling. J. Endocr. 34, 197-214

FORSLING, M.L., MACDONALD, A.A. and ELLENDORFF, F. (1979). The neurohypophysial hormones. Anim. Reprod. Sci. 2, 43-56

FORSLING, M.L., TAVERNE, M.A.M., PARVIZI, N., ELSAESSER, F., SMIDT, D. and ELLENDORFF, F. (1979). Plasma oxytocin and steroid concentrations during later pregnancy, parturition and lactation in the miniature pig. $J$. Endocr. 82, 61-69

FRASER, D. (1973). The nursing and suckling behaviour of pigs. I. The importance of stimulation of the anterior teats. Br. vet. J. 129, 324-336

KONDA, N., DYER, R.G., BRUHN, T., MACDONALD, A.A. and ELLENDORFF, F. (1979). A method for recording single unit activity from the brains of foetal pigs in utero. J. Neurosci. Methods 1, 289-300

LADEWIG, J., PRICE, E.O. and HART, B.L. (1980). Flehmen in male goats: role in sexual behaviour. Behavl Neur. Biol. 30, 312-322

LINCOLN, D.W. HENTZEN, K., HIN, T., VAN DER SCHOOT, P., CLARKE, G. and SUMMERLEE, A.J.S. (1980). Sleep a prerequisite for reflex milk ejection in the rat. Exp. Brain Res. 38, 151-162

MACDONALD, A.A., FORSLING, M.L., WILLIAMS, H. and ELLENDORFF, F. (1979). Plasma vasopressin and oxytocin concentrations in the conscious pig foetus: response to haemorrhage. $J$. Endocr. 81, 124P-125P

MACLEOD, N., REINHARDT, W. and ELLENDORFF, F. (1979). Olfactory bulb neurons of the pig respond to an identified steroidal pheromone and testosterone. Brain Res. 164, 323-327

PARVIZI, N. and ELLENDORFF, F. (1975). 2-Hydroxy-oestradiol-17 $\beta$ as a possible link in steroid brain interaction. Nature, Lond. 256, 59-60

PARVIZI, N. and ELLENDORFF, F. (1978). Norepinephrine and luteinizing hormone secretion: intrahypothalamic and intraventricular microinjection of norepinephrine. Brain Res. 148, 521-525

PARVIZI, N. and ELLENDORFF, F. (1980a). Gonadal steroids in the amygdala - differential effects on LH. Brain Res. 195, 363-372

PARVIZI, N. and ELLENDORFF, F. (1980b). $\beta$-Endorphin alters luteinizing hormone secretion via the amygdala but not the hypothalamus. Nature, Lond. 286, 812-813

PARVIZI, N., ELSAESSER, F., SMIDT, D. and ELLENDORFF, F. (1977). Effects of intracerebral implantation, microinjection, and peripheral application of sexual steroids on plasma luteinizing hormone levels in the male miniature pig. Endocrinology 101, 1078-1087

POMERANTZ, D.K., ELLENDORFF, F., ELSAESSER, F, KONIG, A. and SMIDT, D. (1974). Plasma LH changes in intact adult, castrated adult and pubertal male pigs following various doses of synthetic luteinizing hormonereleasing hormone (LH-RH). Endocrinology 94, 330-335 
POULAIN, D.A., RODRIGUEZ, F. and ELLENDORFF, F. (1981). Sleep is not a prerequisite for the milk ejection reflex in the pig. Exp. Brain Res. 43, $107-110$

REINHARDT, W., KONDA, N., MACLEOD, N. and ELLENDORFF, F. (1981). Electrophysiology of olfacto-limbic-hypothalamic connections in the pig. Exp. Brain Res. 43, 1-10

SCHALLY, A.V., ARIMURA, A., BABA, Y., MAIR, R.M.G., MATSUO, H., REDDING, T.W., DEBELJUK, L. and WHITE, W.F. (1971). Isolation and properties of the FSH and LH-releasing hormone. Biochem. Biophys. Res. Commun. 43, 393-399

SCHNEIDER, H.P.G. and MCCANN, S.M. (1970). Mono- and indolamines and control of LH-secretion. Endocrinology 86, 1127-1133

SHEARER, I.G., PURVIS, K., JENKINS, G. and HAYNES, N.B. (1972). Peripheral plasma progesterone and oestradiol-17 $\beta$ levels before and after puberty in gilts. J. Reprod. Fert. 30, 347-360

SILVER, M., BARNES, R.J., COMLINE, R.S., FOWDEN, A.L., CLOVER, L. and MITCHELL, M.D. (1979). Prostaglandins in the foetal pig and prepartum endocrine changes in mother and foetus. Anim. Reprod. Sci. 2, 305-322

TAVERNE, M.A.M., NAAKTGEBOREN, C., ELSAESSER, F., FORSLING, M.L., VAN DER WEYDEN, G.C., ELLENDORFF, F. and SMIDT, D. (1979). Myometrial electrical activity and plasma concentrations of progesterone, estrogens and oxytocin during late pregnancy and parturition in the miniature pig. Biol. Reprod. 21, 1125-1134

THORBURN, G.D., CHALLIS, J.R.G. and CURRIE, w.B. (1977). Control of parturition in domestic animals. Biol. Reprod. 16, 18-27

VINGNEAUD DU, V., BARLETT, M.F. and JOHL, A. (1954-1955). Hormones of the posterior pituitary gland: Oxytocin and vasopressin. Harvey Lect. 50, $1-26$

VOLOSCHIN, L.M. and TRAMEZZANI, J.H. (1979). Milk ejection reflex linked to slow wave sleep in nursing rats. Endocrinology 105, 1202-1207

WHITTLESTONE, w.B. (1954). Intramammary pressure changes in the lactating sow. I. Effect of oxytocin. J. Dairy Res. 21, 19-30 